\title{
Immunoglobulin A nephropathy and ischemic heart disease: a nationwide population-based cohort study
}

Simon Jarrick ${ }^{1,2}$, Sigrid Lundberg ${ }^{3,4}$, Johan Sundström ${ }^{5,6}$, Adina Symreng ${ }^{7}$, Anna Warnqvist ${ }^{8}$ and Jonas F. Ludvigsson ${ }^{1,9,10,11^{*}}$

\begin{abstract}
Background: Chronic kidney disease has been linked to cardiovascular disease and specifically ischemic heart disease (IHD), but large-scale population data in patients with immunoglobulin A nephropathy (IgAN) are missing.

Objective: To examine absolute and relative risks for IHD in patients with IgAN.

Methods: Population-based register-based cohort study in Sweden. We identified 3945 patients with biopsy-verified IgAN, and 19,272 age- and sex-matched reference individuals from the general population. To reduce residual confounding from genetic factors and early environmental factors we carried out secondary analyses, where we compared 3039 IgAN patients with 6729 siblings, whereas a spousal analysis consisted of 2377 married couples where one of the spouses had IgAN. Data on IHD and end-stage renal disease (ESRD) were retrieved from the nationwide Patient Register. Cox regression estimated hazard ratios (HRs) adjusted for matching variables, education, country of birth, cancer, diabetes mellitus, and other systemic inflammatory diseases.

Results: During a follow-up of 55,527 person-years (py; mean follow-up 14.1 years), 371 patients (9.4\%) with IgAN developed IHD (6.7/1000 py), compared with 1070 (5.6\%) in 287,677 py in reference individuals (3.7/1000 py). The corresponding adjusted HR was $1.86(95 \% \mathrm{Cl}=1.63-2.13)$, equivalent to one extra case of IHD per 34 IgAN patients followed-up for 10 years. HRs were similar in men and women with IgAN, but higher in the first year after diagnosis and in patients born outside the Nordic countries. Patients with IgAN were at increased risk of IHD also compared to siblings $(\mathrm{HR}=2.07 ; 95 \% \mathrm{Cl}=1.62-2-64)$ and spouses $(\mathrm{HR}=1.91 ; 95 \% \mathrm{Cl}=1.40-2.61)$.
\end{abstract}

Conclusions: In this nationwide population-based study, patients with IgAN were at an $86 \%$ increased risk of future IHD.

\section{Introduction}

Immunoglobulin A nephropathy (IgAN) is recognized as the most common primary glomerulonephritis worldwide $[1,2]$, and as such contributes significantly to the global burden of chronic kidney disease (CKD) [2, 3]. As CKD is associated with increased risks of cardiovascular disease

\footnotetext{
* Correspondence: jonasludvigsson@yahoo.com

1 Department of Pediatrics, Örebro University Hospital, Örebro, Sweden

${ }^{9}$ Department of Medical Epidemiology and Biostatistics, Karolinska Institutet, SE-17177 Stockholm, Sweden

Full list of author information is available at the end of the article
}

and death [4-6], this could be expected also in patients with IgAN. IgAN is also associated with other known risk factors for cardiovascular disease, including hypertension, proteinuria and hyperuricemia [7]. Increases in both systemic and vascular markers of inflammation [8] and in arterial stiffness [9] have been demonstrated even in early IgAN. Nevertheless, the association between cardiovascular disease and IgAN has not been extensively studied, other than in the particular case of end-stage renal disease (ESRD). One study by Myllymäki et al. demonstrated high

C C The Author(s). 2021 Open Access This article is licensed under a Creative Commons Attribution 4.0 International License, which permits use, sharing, adaptation, distribution and reproduction in any medium or format, as long as you give appropriate credit to the original author(s) and the source, provide a link to the Creative Commons licence, and indicate if changes were made. The images or other third party material in this article are included in the article's Creative Commons licence, unless indicated otherwise in a credit line to the material. If material is not included in the article's Creative Commons licence and your intended use is not permitted by statutory regulation or exceeds the permitted use, you will need to obtain permission directly from the copyright holder. To view a copy of this licence, visit http://creativecommons.org/licenses/by/4.0/ The Creative Commons Public Domain Dedication waiver (http://creativecommons.org/publicdomain/zero/1.0/) applies to the data made available in this article, unless otherwise stated in a credit line to the data. 
rates of IHD and cerebrovascular disease in a cohort of 220 patients with biopsy-proven IgAN, although outcomes were not identically defined in exposed and unexposed groups [10].

In a large, nationwide cohort of patients with biopsyproven IgAN, we recently demonstrated increased overall and cardiovascular mortality, compared with the matched general population [11]. The current study uses the same cohort to examine incident cardiovascular disease in IgAN. The aim of the study was to examine fatal or nonfatal IHD in patients with IgAN compared with a matched reference population, by linking biopsy data to national health registers. Additional comparisons with siblings and spouses allowed us to reduce confounding due to shared risk factors within families and increase our understanding of IgAN and cardiovascular disease even further. We hypothesized that patients are at increased risk of IHD.

\section{Materials and methods}

\section{Registers}

The Swedish personal identity number is a unique 10digit code assigned to every Swedish resident at birth or immigration. The personal identity number enables largescale data linkages of multiple national registers [12].

The Swedish Total Population Register [13] contains demographic data on all Swedish residents, including dates of birth, death, immigration and emigration, place of birth and residence, sex, spouse, and educational level. The Total Population Register also includes the MultiGeneration Register, linking all first-degree relatives to all individuals born in Sweden since 1932 who were still alive in 1961.

The Swedish National Patient Register lists hospital stays since 1964, with national coverage since 1987, and hospital outpatient visits since 2001. The register contains information on admission and discharge, main and additional diagnoses, and surgical procedures, with corresponding International Classification of Diseases (ICD) codes and procedure codes. A validation of the Patient Register confirmed a high diagnostic accuracy of 8595\% for most diagnoses, with more severe diagnoses tending to be more accurate [14].

The Swedish Cause of Death Register was started in 1952, with complete coverage since 1961. Registration of the cause of death must be completed within 3 weeks from the death certificate, and is fulfilled in about $99.5 \%$ of deceased (the ICD code R99.9 is used for the remaining $0.5 \%$ ) [15].

The Swedish Prescribed Drug Register contains information about drug expenditures for prescribed drugs in the entire Swedish population, from July 1, 2005, onwards. Hospitaladministered drugs and over-the-counter medications are not included. Patient identity data are available for $99.7 \%$ of all records [16].

\section{Definition of IgAN and inclusion of patients}

We defined IgAN as having a biopsy record of IgAN (1974-2011) at any of the four pathology departments where all renal biopsy specimens in Sweden are evaluated. In 3 units (Stockholm, Gothenburg, and Linköping), biopsy records where screened for the SnoMed CT (Systematized Nomenclature of Medicine - Clinical Term) codes D67300 (IgAN) and T71000 (kidney) [17]. One unit (Malmö/Lund) did not provide SNOMED codes, and biopsy reports from this region were reviewed manually (see Welander et al. [18] for a detailed description). The resulting cohort of 4125 individuals with a biopsy report of IgAN was validated through manual review of complete patient charts from a random subset of 127 patients, confirming the diagnosis in 95.3\% (95\% confidence interval (CI): 91.6-98.9\%) of the cases [19]. Since we studied first occurrence of IHD as the outcome, we excluded all IgAN patients and all primary and secondary reference individuals with the ICD codes corresponding to IHD before inclusion date (see supplemental eTable S2 for definitions).

\section{Matched reference individuals (controls)}

For each patient with IgAN, the government agency Statistics Sweden (SCB) identified up to five reference individuals from the Total Population Register matched for age, sex, calendar year, and county of residence at the time of renal biopsy in the index patient. Controls with IgAN at inclusion were excluded.

\section{Secondary comparison groups}

To account for residual confounding factors that could not be statistically adjusted for, we used the multigeneration register to identify secondary comparison groups that could be expected to share genetic, environmental and behavioral risk factors with the IgAN patients. Thus, patients with IgAN were compared with siblings and spouses (defined as the first person an IgAN patient was legally married to). IgAN patients without siblings, or who were never married, were excluded from the respective analyses. We also excluded relatives with IgAN at inclusion.

\section{Follow-up}

The date of IgAN diagnosis was defined as the date of the first renal biopsy indicating IgAN. Follow-up in IgAN patients began at diagnosis and on the same date in matched reference individuals, siblings and spouses, and ended with studied outcome under examination, death, emigration, or May 312,017, whichever occurred first. 


\section{Outcomes}

Our main outcome was the first instance of any IHD, defined as the occurrence of either myocardial infarction or angina pectoris (please see supplemental eTable S2 for corresponding ICD codes) in the patient register, or as the underlying (but not as of the contributory) cause in the Cause of Death Register. We also studied myocardial infarction separately.

\section{Covariates}

We collected information on relevant demographic and clinical factors present at inclusion, which could influence cardiovascular risk as possible confounders. Data on sex, country of birth, and educational level were retrieved from the Total Population Register. Data on relevant comorbidity (diabetes, cancer, systemic inflammatory diseases other than IgAN and cardiovascular disease other than IHD and hypertension) were extracted from the Patient Register. Heredity for IgAN was defined as having $\geq 1$ first-degree relative with a biopsy report of IgAN before study entry of the index individual. First-degree relative were identified through the multigeneration register and did not include spouses.

ESRD was defined as the first occurrence in the patient register of any ICD code for CKD stage 5, or any ICD code or procedure code associated with dialysis or kidney transplantation (supplemental eTable S3). To increase specificity, three or more records of an ESRD diagnosis were required, with at least 4 months between the first and the last diagnosis.

As hypertension is commonly caused by chronic kidney disease including IgAN, and a known risk factor for IHD, it was considered as a mediator rather than a confounder and not adjusted for in the models.

\section{Statistical analysis}

We used Cox regression with internal stratification (each IgAN individual was compared with his or her matched reference individuals) to calculate hazard ratios (HRs) for any IHD (our main outcome) as well as myocardial infarction. Since proportionality over time was not verified statistically, HRs were considered as estimates of the geometric mean of the true, changing HRs [20], but we also presented HRs in the first year of follow-up.

Event-free survival was presented graphically using Cox adjusted survival diagrams.

All analyses were adjusted for educational level $(\leq 9$, 9-12, and $\geq 13$ years), country of birth (Nordic, including Sweden, vs. non-Nordic countries), and the presence at baseline of cardiovascular disease, cancer, diabetes mellitus, and other systemic inflammatory diseases (supplementary eTable S1 for definitions). Comparisons with general population reference individuals were also adjusted for heredity for IgAN and ESRD. As sibling and spousal analyses could not be matched for sex and age, these analyses were instead adjusted for in the Cox model. Throughout the study, we exclusively report adjusted HRs. We also calculated IHD- and diseasespecific incidence rates per 1000 person-years (py) in IgAN patients and reference individuals, and present absolute excess rates (unadjusted).

We used Stata Statistical Software, release 15 (StataCorp LP, College Station, TX) for the statistical calculations. $P$ values $<0.05$ were considered statistically significant.

\section{Ethics}

The study was approved by the Stockholm Ethics Review Board (January 22, 2014; Dnr 2013/2095-31/2). Because this was a strictly register-based study, informed consent was waivered by the Board [21]. The current study was carried out in accordance with relevant guidelines and regulations.

\section{Results \\ Demographics and background variables}

We identified 4125 individuals with IgAN. After exclusion of 180 individuals with IHD before inclusion date, 3945 were included in the final analyses (Table 1). Extrarenal manifestations of IgA vasculitis (Henoch-Schönlein purpura) were present in 170 (4.3\%). Those 3945 patients were compared to 19,272 matched reference individuals (main analysis). The sibling analysis compared 3039 IgAN patients with 6729 siblings, whereas the spousal analysis consisted of 2377 married couples.

In the main analysis, the median age at inclusion in both groups was 39 years. The male to female ratio among IgAN patients was 2.4:1. The mean (standard deviation) follow-up time was 14.1 (8.5) years for IgAN patients versus 14.9 (8.5) years for reference individuals, with similar follow-up in sibling and spousal analyses. Other demographic characteristics were similar between groups. Among IgAN patients, 1241 (31.5\%) had a diagnosis of hypertension, compared to 344 (1.8\%) among matched reference individuals. Diabetes and concomitant systemic inflammatory disease were more common in IgAN patients compared to all comparison groups.

Hypertension was present in $31.5 \%$ of the IgAN patients and $1.8 \%$ of the reference individuals at inclusion, and $50.1 \%$ of IgAN patients had a hypertension diagnosis any time during follow-up. Among 1343 IgAN patients included after July 12,005 when we had access to data on medication, glucocorticoids were prescribed to 784 (58.4\%), and other immunosuppressive drugs to 345 (25.7\%) patients during follow-up, and for 178 (13.3\%) and $93(6.9 \%)$ patients during the first year after biopsy. Reninangiotensin-aldosterone system inhibitors (RAASi) were used in 1172 (87.3\%) and other antihypertensive drugs in 841 (62.3\%) IgAN patients, and in 516 (38.4\%) and 354 
Table 1 Descriptive baseline characteristics of patients with IgAN compared to matched general population reference individuals, siblings and spouses

\begin{tabular}{|c|c|c|c|c|c|c|}
\hline & \multicolumn{2}{|l|}{ Main analysis } & \multicolumn{2}{|l|}{ Sibling analysis } & \multicolumn{2}{|l|}{ Spousal analysis } \\
\hline & $\operatorname{IgAN}$ & $\begin{array}{l}\text { General population } \\
\text { reference }\end{array}$ & $\lg A N$ & Siblings & $\lg A N$ & Spouses \\
\hline & $n(\%)$ & $n(\%)$ & $n(\%)$ & $n(\%)$ & $n(\%)$ & $n(\%)$ \\
\hline Total & 3945 & 19,272 & 3039 & 6729 & 2377 & 2377 \\
\hline Person-years (py) & 55,527 & 287,677 & 44,796 & 105,096 & $35,484(0)$ & $38,893(0)$ \\
\hline \multicolumn{7}{|l|}{ Sex } \\
\hline Female & 1172 (29.7\%) & $5780(30.0 \%)$ & $869(28.6 \%)$ & 3307 (49.1\%) & $690(29.0 \%)$ & 1710 (71.9\%) \\
\hline Male & 2773 (70.3\%) & 13,492 70.0\%) & $2170(71.4 \%)$ & 3422 (50.9\%) & 1687 (71.0\%) & $667(28.1 \%)$ \\
\hline \multicolumn{7}{|l|}{ Age } \\
\hline Age, mean (SD) & $39.4(16.5)$ & $38.9(16.2)$ & $35.9(14.9)$ & $35.3(16.6)$ & $43.5(14.3)$ & $42.9(14.6)$ \\
\hline Age, median (IQR) & $38.9(26.5,51.3)$ & $38.3(26.2,50.5)$ & $35.3(23.9,47)$ & $35.7(23,47.9)$ & $43.1(32.7,53.9)$ & $42.8(32.3,53.2)$ \\
\hline$\leq 17$ years & $380(9.6 \%)$ & $1894(9.8 \%)$ & 361 (11.9\%) & $1093(16.2 \%)$ & $64(2.7 \%)$ & $91(3.8 \%)$ \\
\hline 18-39years & 1706 (43.2\%) & 8541 (44.3\%) & 1485 (48.9\%) & $2872(42.7 \%)$ & $943(39.7 \%)$ & 947 (39.8\%) \\
\hline 40-59years & 1390 (35.2\%) & 6778 (35.2\%) & 1015 (33.4\%) & 2312 (34.4\%) & 1046 (44.0\%) & $1036(43.6 \%)$ \\
\hline$\geq 60$ years & $469(11.9 \%)$ & 2059 (10.7\%) & $178(5.9 \%)$ & $452(6.7 \%)$ & $324(13.6 \%)$ & $296(12.5 \%)$ \\
\hline Unknown & & & & & $0(0.0 \%)$ & $7(0.3 \%)$ \\
\hline \multicolumn{7}{|l|}{ Year of inclusion } \\
\hline Entry year, median (IQR) & $\begin{array}{l}2001(1994, \\
2007)\end{array}$ & $2001(1994,2007)$ & $\begin{array}{l}2002(1994, \\
2008)\end{array}$ & $\begin{array}{l}2001(1994, \\
2007)\end{array}$ & $\begin{array}{l}2000(1993, \\
2006)\end{array}$ & $\begin{array}{l}2000(1993, \\
2006)\end{array}$ \\
\hline 1974-1988 & $438(11.1 \%)$ & $2168(11.2 \%)$ & $317(10.4 \%)$ & $728(10.8 \%)$ & $326(13.7 \%)$ & $326(13.7 \%)$ \\
\hline 1989-2001 & 1565 (39.7\%) & 7662 (39.8\%) & $1187(39.1 \%)$ & $2670(39.7 \%)$ & $1024(43.1 \%)$ & $1024(43.1 \%)$ \\
\hline $2002-2015$ & $1942(49.2 \%)$ & $9442(49.0 \%)$ & 1535 (50.5\%) & $3331(49.5 \%)$ & 1027 (43.2\%) & $1027(43.2 \%)$ \\
\hline \multicolumn{7}{|l|}{ Follow up time } \\
\hline Mean (SD) & $14.1(8.47)$ & $14.9(8.52)$ & $14.7(8.49)$ & $15.6(8.51)$ & $14.9(8.76)$ & $16.4(8.67)$ \\
\hline Median (IQR) & $12.7(7.45,19.6)$ & $13.7(8.11,20.7)$ & $13.5(7.99,20.4)$ & $14.5(8.61,21.5)$ & $13.8(8.01,20.7)$ & $15.5(9.3,22.5)$ \\
\hline $0-1$ years & $79(2.0 \%)$ & $194(1.0 \%)$ & $35(1.2 \%)$ & $41(0.6 \%)$ & $56(2.4 \%)$ & $20(0.8 \%)$ \\
\hline $1-4$ years & $464(11.8 \%)$ & 2001 (10.4\%) & $314(10.3 \%)$ & $569(8.5 \%)$ & $248(10.4 \%)$ & $176(7.4 \%)$ \\
\hline$\geq 5$ years & 3402 (86.2\%) & 17,077 88.6\%) & $2690(88.5 \%)$ & $6119(90.9 \%)$ & $2073(87.2 \%)$ & $2181(91.8 \%)$ \\
\hline \multicolumn{7}{|l|}{ Reason for end of follow up } \\
\hline May 31, 2017 & $3022(76.6 \%)$ & $16,00083.0 \%)$ & $2524(83.1 \%)$ & $6020(89.5 \%)$ & $1759(74.0 \%)$ & $2021(85.0 \%)$ \\
\hline Emigration & $105(2.7 \%)$ & $727(3.8 \%)$ & $80(2.6 \%)$ & $160(2.4 \%)$ & $48(2.0 \%)$ & $45(1.9 \%)$ \\
\hline IHD (death or diagnosis) & $371(9.4 \%)$ & $1070(5.6 \%)$ & $206(6.8 \%)$ & $242(3.6 \%)$ & $290(12.2 \%)$ & $126(5.3 \%)$ \\
\hline Death from other cause & $447(11.3 \%)$ & $1475(7.7 \%)$ & $229(7.5 \%)$ & $307(4.6 \%)$ & $280(11.8 \%)$ & $185(7.8 \%)$ \\
\hline \multicolumn{7}{|l|}{ Country of birth } \\
\hline Nordic & $3602(91.3 \%)$ & 17,322 89.9\%) & $2971(97.8 \%)$ & $6568(97.6 \%)$ & $2128(89.5 \%)$ & $2085(87.7 \%)$ \\
\hline Non-Nordic & $342(8.7 \%)$ & $1948(10.1 \%)$ & $68(2.2 \%)$ & $161(2.4 \%)$ & $249(10.5 \%)$ & $229(9.6 \%)$ \\
\hline Unknown & $1(<1 \%)$ & $2(<1 \%)$ & $0(0.0 \%)$ & $0(0.0 \%)$ & $0(0.0 \%)$ & $63(2.7 \%)$ \\
\hline \multicolumn{7}{|l|}{ Level of education } \\
\hline Compulsory school (0-9years) & $817(20.7 \%)$ & $3852(20.0 \%)$ & $506(16.7 \%)$ & $1195(17.8 \%)$ & $527(22.2 \%)$ & $435(18.3 \%)$ \\
\hline Upper sec. School (10-12 years) & 1759 (44.6\%) & $8690(45.1 \%)$ & 1415 (46.6\%) & $3205(47.6 \%)$ & 1007 (42.4\%) & $1044(43.9 \%)$ \\
\hline University (> 12 years) & $1276(32.3 \%)$ & $6279(32.6 \%)$ & $1066(35.1 \%)$ & $2090(31.1 \%)$ & $816(34.3 \%)$ & $817(34.4 \%)$ \\
\hline Unknown & $93(2.4 \%)$ & $451(2.3 \%)$ & $52(1.7 \%)$ & $239(3.6 \%)$ & $27(1.1 \%)$ & 81 (3.4\%) \\
\hline \multicolumn{7}{|l|}{ Comorbitity $^{a}$} \\
\hline $\mathrm{HSP} / \mathrm{lg} A V^{b}$ & $236(6.0 \%)$ & $30(0.2 \%)$ & $203(6.7 \%)$ & $22(0.3 \%)$ & $94(4.0 \%)$ & $5(0.2 \%)$ \\
\hline
\end{tabular}


Table 1 Descriptive baseline characteristics of patients with IgAN compared to matched general population reference individuals, siblings and spouses (Continued)

\begin{tabular}{|c|c|c|c|c|c|c|}
\hline & \multicolumn{2}{|l|}{ Main analysis } & \multicolumn{2}{|c|}{ Sibling analysis } & \multicolumn{2}{|c|}{ Spousal analysis } \\
\hline & $\lg A N$ & $\begin{array}{l}\text { General population } \\
\text { reference }\end{array}$ & $\lg A N$ & Siblings & IgAN & Spouses \\
\hline Diabetes, type 1 or 2 & $170(4.3 \%)$ & $309(1.6 \%)$ & $97(3.2 \%)$ & $107(1.6 \%)$ & $101(4.2 \%)$ & $45(1.9 \%)$ \\
\hline $\begin{array}{l}\text { Other systemic inflammatory } \\
\text { disease }\end{array}$ & $313(7.9 \%)$ & $459(2.4 \%)$ & $224(7.4 \%)$ & $207(3.1 \%)$ & $193(8.1 \%)$ & $77(3.2 \%)$ \\
\hline Hypertension & 1241 (31.5\%) & $344(1.8 \%)$ & 891 (29.3\%) & $139(2.1 \%)$ & 809 (34.0\%) & $51(2.1 \%)$ \\
\hline Heredity for IgAN & $38(1.0 \%)$ & $28(0.1 \%)$ & & & & \\
\hline Heredity for ESRD & $84(2.1 \%)$ & $139(0.7 \%)$ & & & & \\
\hline
\end{tabular}

Continuous parameters are presented as mean values with standard deviations. Categorical values are presented as numbers and percentages. For all definitions, see main text or Additional file 1

${ }^{a}$ Before study inclusion date (biopsy date in IgAN patients and corresponding date in reference individuals)

${ }^{\mathrm{b}} \mathrm{HSP} / \mathrm{IgAV}$ Henoch-Schönlein's purpura, or systemic IgA vasculitis

(26.4\%) respectively during the first year. Statins were prescribed to $578(43.0 \%)$ patients during follow-up, and to $162(12.1 \%)$ in the first year (supplemental eTable S4).

\section{Main outcome: any ischemic heart disease (IHD)}

During a follow-up of 55,527 person-years (py), 371 patients $(9.4 \%)$ with IgAN had at least one record of any IHD (6.7 per 1000 py), compared with 1070 (5.6\%) during 287,677 py in reference individuals (3.7 per 1000 py) (Figs. 1 and 2, supplemental eTable S5). The unadjusted absolute excess rate was 3.0 per 1000 py. The corresponding adjusted $\mathrm{HR}$ was $1.86(95 \% \mathrm{CI}=1.63-2.13)$, equivalent to one extra case of IHD per 34 IgAN patients followed- up for 10 years. The HRs were similar across subgroups. The rate of IHD was higher in the first year after inclusion (8.5 per 1000 py; $\mathrm{HR}=2.63(95 \% \mathrm{CI}=1.57-4.41))$, and increased both among Nordic (6.58 per 1000 py; HR $=1.83$ $(95 \% \mathrm{CI}=1.59-2.1))$ and non-Nordic individuals $(7.97 \mathrm{per}$ 1000 py; $\mathrm{HR}=2.52(95 \% \mathrm{CI}=1.53-4.14))$. The HR for IHD did not differ significantly between women $(1.72 ; 95 \% \mathrm{CI}=$ 1.24-2.37) and men $(1.90 ; 95 \% \mathrm{CI}=1.64-2.21)$. For all other strata, HRs were of the same magnitude compared to the general population reference individuals. Risk estimates were generally similar when IgAN patients were compared to their siblings $(\mathrm{HR}=2.07 ; 95 \% \mathrm{CI}=1.62-2-64)$ (supplemental eTable S6) and spouses (HR $=1.91$;
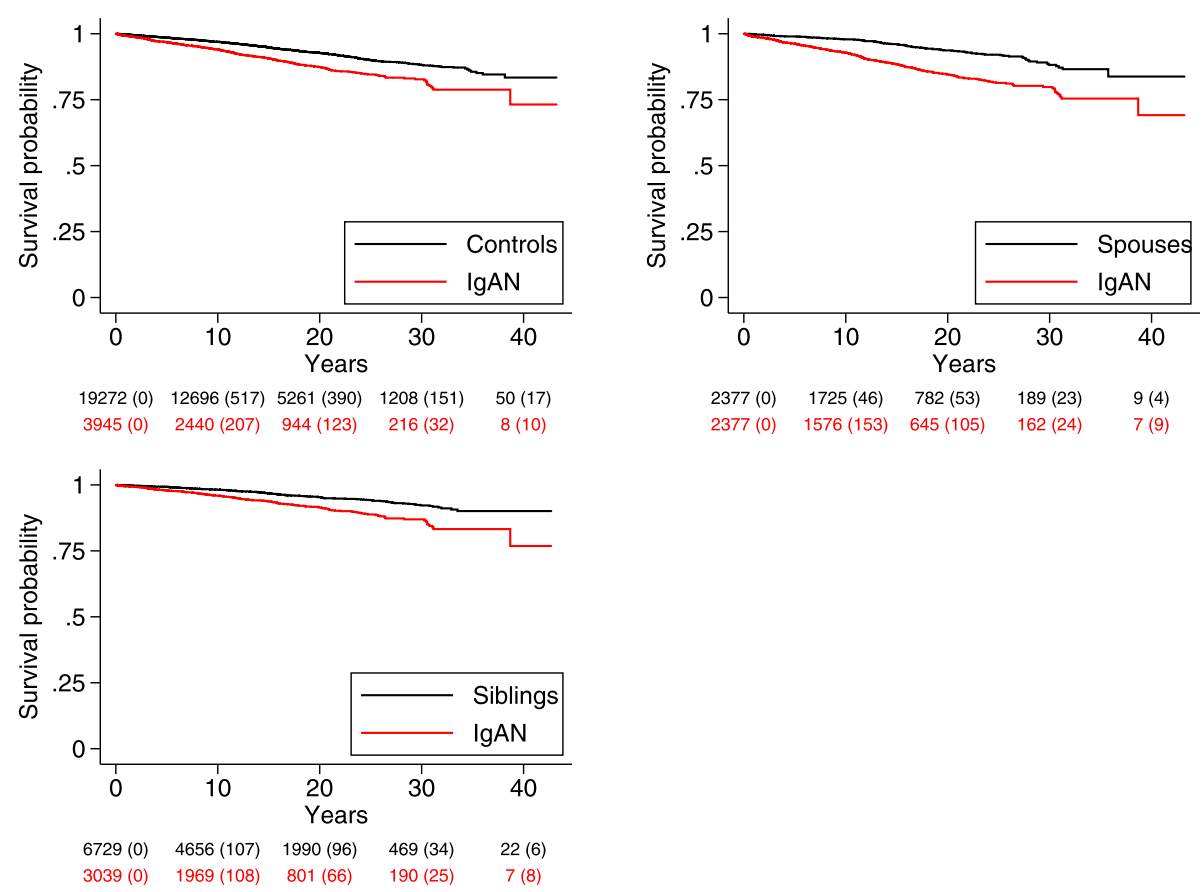

Fig. 1 Event-free survival in patients with IgA nephropathy, compared with matched reference individuals, siblings and spouses, presented as Kaplan-Meier diagrams, with ischemic heart disease as outcome 


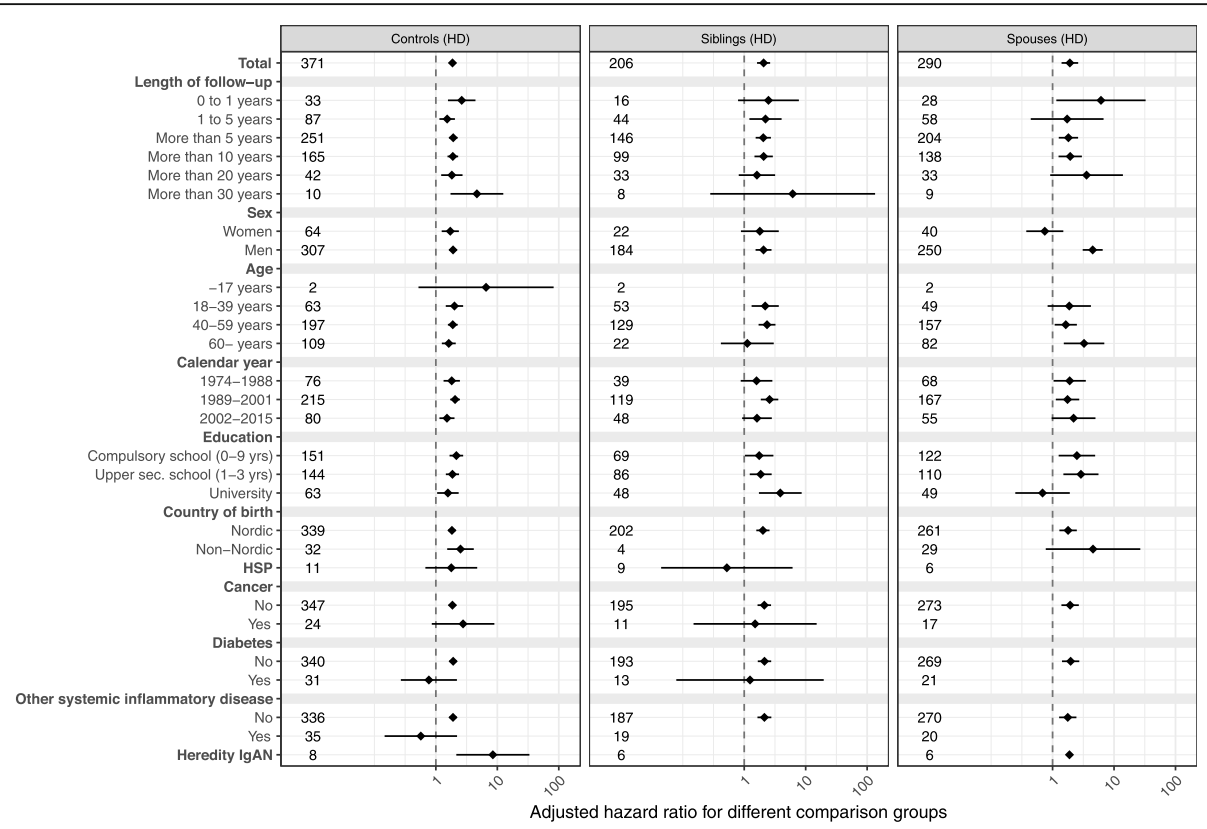

Fig. 2 Forrest plots presenting adjusted hazard ratios for ischemic heart disease in IgA nephropathy compared to general population controls, siblings and spouses. Legend: HSP, Henoch-Schönlein Purpura

$95 \% \mathrm{CI}=1.40-2.61$, with the exception of a significantly higher HR for IHD in men than in women in spousal analysis (supplemental eTable S7).

\section{Secondary outcome: myocardial infarction (MI)}

Restricting the outcome to myocardial infarction (MI), there were 216 events (5.5\%) during 56,865 py in IgA patients, versus 662 events (3.4\%) during 291,433 py in reference individuals, with an unadjusted absolute excess rate of 1.5 per 1000 py (one case in 65 individuals followed for 10 years), and a corresponding adjusted HR (aHR) of $1.83(95 \% \mathrm{CI}=1.54-2.18)$ (supplemental eTable S8). Non-Nordic origin was associated with a higher $\operatorname{aHR}(3.67 ; 95 \% \mathrm{CI}=1.37-9.84)$.

\section{Discussion}

In the current nation-wide, population-based study including more than 3900 patients diagnosed with IgAN in Sweden over a study period of 37 years, we found an $86 \%$ increased risk of IHD, equivalent to one extra case of IHD per 34 IgAN patients followed-up for 10 years. The IHD excess risk was present across a range of IgAN sub-populations and compared to siblings and spouses. Similar HRs were seen for myocardial infarction.

Previous studies have shown vascular changes with increased arterial stiffness in IgAN patients even at early stages $[9,22]$. Consistently, we found hypertension in almost one third of IgAN patients already at the time of biopsy, compared to less than $2 \%$ in a matched reference population, and half of the patients had hypertension during follow up (according to ICD code; $87 \%$ were prescribed RAAS inhibitors, which might have been intended also for treatment of proteinuria, and $62 \%$ other antihypertensive drugs). There is also robust evidence that CKD patients experience a risk increase for cardiovascular events and death with increasing CKD stage, long before they reach ESRD [4-6, 23]. Indeed, one Finnish study found tripled odds for cardiovascular disease in IgAN patients compared with an age- and sex-matched reference population derived from national health survey data and doubled odds when only IgAN patients with stable nonprogressive kidney disease were included [10]. The deviation from our results might in part be due to a different patient selection (we used national biopsy data and did not rely on tertiary center data), our use of biopsy records to define IgAN (positive predictive value $=95 \%$ [19]), and that the Finnish study derived their reference population from survey interviews, while we relied on national health registers with physician-reported data.

After adjusting for potential confounders including prevalent comorbidity, we found similar HRs in both men (1.72) and women (1.90). We also noted a strong association between IgAN and IHD in the first year after IgAN. This may reflect a more intense clinical work-up for symptoms suggestive of IHD when the IgAN patients have frequent healthcare visits. We chose to examine IHD-naïve IgAN patients and hence excluded individuals with a prior IHD diagnosis. We did so to be able to estimate the future risk of IHD in IgAN, a topic of interest to many patients. 


\section{Strengths and limitations}

We followed more than 3900 IgAN patients and 19,200 reference individuals for a mean follow up time of $>14$ years. Through linkage to the personal identity number we virtually eliminated loss of follow-up using nationwide registers on emigration status, and death. The number of IHD cases in IgAN $(n=371)$ to our knowledge exceeds the total number reported in the literature up to date. This allowed us to calculate both relative and absolute risks with substantial precision. We were able to demonstrate a clearly increased risk $(\mathrm{HR}=1.86)$, but also to rule out huge excess risks (the upper $95 \% \mathrm{CI}$ in our study signals that a more than 2.2-fold risk increase is unlikely). Our absolute risk estimates will help physicians convey an understandable message to IgAN patients (one extra case of IHD in 34 IgAN patients followed-up for 10 years). The nationwide, populationbased design should minimize selection bias. The Swedish national health registers are well validated and of high quality. Through the Patient Register (positive predictive value for most disorders have been estimated at 85-95\%) [14], we retrieved information on important potential confounders such as diabetes, other inflammatory conditions and cancer. Furthermore, our data were adjusted for education and country of birth. Additionally, the large number of study participants enabled us to carry out stratified analyses which will allow clinicians to optimize information (same HR in women and men but higher HRs in the first year after diagnosis). The inclusion of a reference population matched for sex and calendar year enabled us to perform Cox regression with internal stratification. We compared IgAN patients not only with the general population, but also with their siblings and spouses. Very similar HRs in these secondary comparisons indicate that the increase in IHD is related to IgAN, and not to shared genetic and early environmental factors. Finally, our exposure was confirmed through biopsy. In an earlier validation study, 121/127 (95\%) randomly selected IgAN patents from our cohort had IgAN according to patient chart records. IgA deposits were reported in $97 \%$ of the biopsy records $(n=$ 123), mesangial hypercellularity in $76 \%(n=96)$, C3 deposits in $89 \%(n=113)$.

We also acknowledge some limitations. We did not have information on cardiovascular risk factors such as glomerular filtration rate, proteinuria or precise blood pressure levels, but it can be argued that these intermediates should not be adjusted for, as these factors are to be considered mediators rather than confounders. Still, stratification on such markers of disease severity could have deepened understanding of risk estimates. We also lack information on smoking. As previous studies have found similar smoking patterns in IgAN patients and the general population [24], smoking habits are unlikely to have biased our results. Except for IgAN related to Henoch Schönlein purpura/IgA vasculitis, our data did not let us distinguish primary IgA from secondary forms.

In conclusion, this nationwide population-based study found an $86 \%$ increased risk of future IHD in patients with IgAN.

\section{Abbreviations}

CKD: Chronic kidney disease; ERSD: End-stage Renal disease;

IgAN: Immunoglobulin A nephropathy; IHD: Ischemic heart disease

\section{Supplementary Information}

The online version contains supplementary material available at https://doi. org/10.1186/s12882-021-02353-7.

Additional file 1: Table S1. Internationalclassification of disease (ICD) codes for renal disease, cardiovasculardisease, diabetes, cancer, HenochSchönlein purpura and other systemicinflammatory diseases. Table S2. International classification of disease (ICD) codes for ischemic heart disease. Table S3. Definitionof renal endpoints. Table S4. AnatomicalTherapeutical Chemical (ATC) codes for medications, used for matching to theSwedish Prescribed Drugs register. Table S5. Adjustedhazardratios (HRs) for ischemic heart diseasecompared with the general referencepopulation (corresponding to column 1 in Fig. 2). Table S6. Adjustedhazardratios (HRs) for ischemic heart diseasecompared with siblings (correspondingto column 2 in Fig. 2). Table S7. Adjustedhazardratios (HRs) for ischemic heart diseasecompared with spouses (correspondingto column 3 in Fig. 2). Table S8. Adjustedhazard ratios (HRs) for acute myocardialinfarction compared with the generalreference population.

\section{Acknowledgements \\ None.}

\section{Authors' contributions}

SJ and JFL conceived and designed the study with input from the other authors. SJ and JFL wrote the first draft of the paper. JFL supervised the project. JFL obtained funding for data collection and register-based linkages. AW analyzed the data. All authors interpreted the data and contributed to the writing of the paper. All authors revised and approved the final version. JFL had full access to all the data and takes responsibility for the integrity of the data. AW takes responsibility for the accuracy of the data analyses.

\section{Funding}

Open Access funding provided by Karolinska Institute.

\section{Availability of data and materials}

The data that support the findings of this study are available from the National Board of Health and Welfare, the government agency Statistics Sweden, and the Pathology departments delivering IgAN data, but restrictions apply to the availability of these data, which were used under license for the current study, and so are not publicly available. Data are however available from the authors upon reasonable request and with permission of the National Board of Health and Welfare, the government agency, Statistics Sweden, and the Pathology departments delivering IgAN data.

\section{Declarations}

\section{Ethics approval and consent to participate}

This project (2013/2095-31/2) was approved by the Ethics Review Board in Stockholm, Sweden on January 22, 2014. Because this was a strictly registerbased study, informed consent was waivered by the Board.

Consent for publication

Not applicable. 


\section{Competing interests}

None.

\section{Author details}

'Department of Pediatrics, Örebro University Hospital, Örebro, Sweden.

${ }^{2}$ Faculty of Health and Medicine, Örebro University, Örebro, Sweden.

${ }^{3}$ Department of Nephrology, Danderyd Hospital, Stockholm, Sweden. ${ }^{4}$ Department of Clinical Sciences, Karolinska Institutet, Danderyd Hospital, Stockholm, Sweden. ${ }^{5}$ Department of Medical Sciences, Clinical Epidemiology, Uppsala University, Uppsala, Sweden. ${ }^{6}$ The George Institute for Global Health, University of New South Wales, Sydney, Australia. ${ }^{7}$ Clinical Epidemiology Division, Department of Medicine, Solna, Karolinska Institutet, Stockholm, Sweden. ${ }^{8}$ Division of Biostatistics, Institute of Environmental Medicine, Karolinska Institutet, Stockholm, Sweden. ${ }^{9}$ Department of Medical Epidemiology and Biostatistics, Karolinska Institutet, SE-17177 Stockholm, Sweden. ${ }^{10}$ Division of Epidemiology and Public Health, School of Medicine, University of Nottingham, Nottingham, UK. "1Department of Medicine, Columbia University College of Physicians and Surgeons, New York, NY, USA.

Received: 15 October 2020 Accepted: 12 April 2021

Published online: 05 May 2021

\section{References}

1. Simon P, Ramee M-P, Boulahrouz R, Stanescu C, Charasse C, Seng Ang K, et al. Epidemiologic data of primary glomerular diseases in western France. Kidney Int. 2004:66(3):905-8. https://doi.org/10.1111/j.1523-1755.2004.00834.x.

2. McGrogan A, Franssen CF, de Vries CS. The incidence of primary glomerulonephritis worldwide: a systematic review of the literature. Nephrol Dial Transplant. 2011;26(2):414-30. https://doi.org/10.1093/ndt/gfq665.

3. Pesce F, Schena FP. Worldwide distribution of glomerular diseases: the role of renal biopsy registries. Nephrol Dialysis Transpl. 2010;25(2):334-6. https:// doi.org/10.1093/ndt/gfp620.

4. Bello AK, Hemmelgarn B, Lloyd A, James MT, Manns BJ, Klarenbach S, et al. Alberta kidney dis $\mathrm{N}$ : associations among estimated glomerular filtration rate, proteinuria, and adverse cardiovascular outcomes. Clin J Am Soc Nephrol. 2011;6(6):1418-26. https://doi.org/10.2215/CJN.09741110.

5. Go AS, Chertow GM, Fan DJ, McCulloch CE, Hsu CY. Chronic kidney disease and the risks of death, cardiovascular events, and hospitalization. N Engl J Med. 2004:351(13):1296-305. https://doi.org/10.1056/NEJMoa041031.

6. van der Velde M, Matsushita K, Coresh J, Astor BC, Woodward M, Levey AS, et al. Chronic kidney dis P: lower estimated glomerular filtration rate and higher albuminuria are associated with all-cause and cardiovascular mortality. A collaborative meta-analysis of high-risk population cohorts. Kidney Int. 2011;79(12):1341-52. https://doi.org/10.1038/ki.2010.536.

7. Zhu B, Yu DR, LV JC, Lin Y, Li Q, Yin JZ, et al. Uric acid as a predictor of immunoglobulin a nephropathy progression: a cohort study of 1965 cases. Am J Nephrol. 2018;48(2):127-36. https://doi.org/10.1159/000489962.

8. Nelson CL, Karschimkus CS, Dragicevic G, Packham DK, Wilson AM, O'Neal D, et al. Systemic and vascular inflammation is elevated in early IgA and type 1 diabetic nephropathies and relates to vascular disease risk factors and renal function. Nephrol Dial Transplant. 2005;20(11):2420-6. https://doi.org/10.1 093/ndt/gfio67.

9. Abdi-Ali A, Mann MC, Hemmelgarn BR, MacRae JM, Turin TC, Benediktsson $\mathrm{H}$, et al. IgA nephropathy with early kidney disease is associated with increased arterial stiffness and renin-angiotensin system activity. J ReninAngiotensin-Aldosterone Syst. 2015;16(3):521-8. https://doi.org/10.1177/14 70320313510586.

10. Myllymaki J, Syrjanen J, Helin H, Pasternack A, Kattainen A, Mustonen J. Vascular diseases and their risk factors in IgA nephropathy. Nephrol Dial Transplant. 2006;21(7):1876-82. https://doi.org/10.1093/ndt/gfl062.

11. Jarrick S, Lundberg S, Welander A, Carrero JJ, Hoijer J, Bottai M, et al. Mortality in IgA nephropathy: a Nationwide population-based cohort study. J Am Soc Nephrol. 2019;30(5):866-76. https://doi.org/10.1681/ASN.2018101017.

12. Ludvigsson JF, Otterblad-Olausson P, Pettersson BU, Ekbom A. The Swedish personal identity number: possibilities and pitfalls in healthcare and medical research. Eur J Epidemiol. 2009;24(11):659-67. https://doi.org/10.1007/s1 0654-009-9350-y.

13. Ludvigsson JF, Almqvist C, Bonamy AK, Ljung R, Michaelsson K, Neovius M, et al. Registers of the Swedish total population and their use in medical research. Eur J Epidemiol. 2016;31(2):125-36. https://doi.org/10.1007/s10654016-0117-y.
14. Ludvigsson JF, Andersson E, Ekbom A, Feychting M, Kim JL, Reuterwall C, et al. External review and validation of the Swedish national inpatient register. BMC Public Health. 2011;11(1):450. https://doi.org/10.1186/1471-24 58-11-450.

15. Brooke HL, Talback M, Hornblad J, Johansson LA, Ludvigsson JF, Druid H, et al. The Swedish cause of death register. Eur J Epidemiol. 2017;32(9):76573. https://doi.org/10.1007/s10654-017-0316-1.

16. Wettermark B, Hammar N, Fored CM, Leimanis A, Otterblad Olausson P, Bergman $U$, et al. The new Swedish prescribed drug register-opportunities for pharmacoepidemiological research and experience from the first six months. Pharmacoepidemiol Drug Saf. 2007;16(7):726-35. https://doi.org/1 0.1002/pds.1294

17. SNOMED CT [https://browser.ihtsdotools.org/index-ie.html?perspective= full\&conceptld $1=404684003 \&$ edition $=$ se-edition\&release $=$ v20190531\&server $=$ https://prod-browser-exten.ihtsdotools.org/api/snomed/\&langRefset=46011 000052107]

18. Welander A, Sundelin B, Fored M, Ludvigsson JF. Increased risk of IGA Nephropathy among individuals with celiac disease. J Clin Gastroenterol. 2013:678-83.

19. Jarrick S, Lundberg S, Welander A, Fored CM, Ludvigsson JF. Clinical validation of immunoglobulin a nephropathy diagnosis in Swedish biopsy registers. Clin Epidemiol. 2017;9:67-73. https:/doi.org/10.2147/CLEP.S118730.

20. Persson I, Khamis H. Bias of the cox model hazard ratio. J Mod Appl Stat Methods. 2005;4(1):90-9. https://doi.org/10.22237/jmasm/1114906200.

21. Ludvigsson JF, Haberg SE, Knudsen GP, Lafolie P, Zoega H, Sarkkola C, et al. Ethical aspects of registry-based research in the Nordic countries. Clin Epidemiol. 2015;7:491-508. https://doi.org/10.2147/CLEP.S90589.

22. Kesoi I, Sagi B, Toth OI, Vas T, Fazekas A, Kovacs T, et al. Different effect of IgA nephropathy and polycystic kidney disease on arterial stiffness. Kidney Blood Press Res. 2011;34(3):158-66. https://doi.org/10.1159/000326802.

23. Hallan SI, Matsushita K, Sang Y, Mahmoodi BK, Black C, Ishani A, et al. Age and association of kidney measures with mortality and end-stage renal disease. JAMA. 2012;308(22):2349-60. https://doi.org/10.1001/jama.2012.16817.

24. Lundberg S, Gunnarsson I, Jacobson SH. Impact of the apolipoprotein B/ apolipoprotein A-I ratio on renal outcome in immunoglobulin a nephropathy. Scand J Urol Nephrol. 2012;46(2):148-55. https://doi.org/10.31 09/00365599.2011.644635.

\section{Publisher's Note}

Springer Nature remains neutral with regard to jurisdictional claims in published maps and institutional affiliations.

Ready to submit your research? Choose BMC and benefit from:

- fast, convenient online submission

- thorough peer review by experienced researchers in your field

- rapid publication on acceptance

- support for research data, including large and complex data types

- gold Open Access which fosters wider collaboration and increased citations

- maximum visibility for your research: over $100 \mathrm{M}$ website views per year

At BMC, research is always in progress.

Learn more biomedcentral.com/submissions 